\title{
Numerical Simulation of Flow around a Spur Dike with Free Surface Flow in Fixed Flat Bed
}

\author{
Mukesh Raj Kafle \\ Department of Civil Engineering, Institute of Engineering, Central Campus, Pulchowk, \\ Tribhuvan University, Nepal \\ Corresponding Email: mrkafle@yahoo.com
}

\begin{abstract}
This paper presents a numerical model to simulate two- dimensional flow near a spur-dike. The Computational Fluid Dynamics (CFD) program namely Nays 2D has been used to simulate the flow field in a fixed flat bed around the spur dike introduced into the flow at $90^{\circ}$ to the stream-wise direction. Cubic-Interpolated PseudoParticle (CIP) method was used as finite difference method to analyze the advection terms. In addition, several turbulence closurer models $\mathrm{k}-\varepsilon$ model, zero equation model and constant eddy viscosity model were applied and compared in order to achieve the best result. The simulated results were compared with existing experimental and computed data which agreed satisfactorily. Achieved results can prove that flow structure simulation around a spur dike could be done by Nays 2D numerical modelling very well.
\end{abstract}

Keywords: Spur dike; Numerical model; Fixed bed; CFD; CIP

\section{Introduction}

Groynes or spur dikes are structures used in rivers to protect banks from erosion caused by flow concentration and also to divert or guide the flow. Moreover, the spur dike concentrates flow or increases the mean velocity and sediment transport capacity of a stream. As a result, the spur dike helps maintaining stream alignment and improving navigability. Besides of these classical roles, the spur dike is known to enhance aquatic habitat by creating pools in a stream [7]. This newly highlighting role of spur dike is very important to restoring streams in which the ecosystem has been deteriorated by rapid industrialization and urbanization in some developing countries.

Modelling the flow near a spur dike is important, especially, associated with developing scour hole and deposition of sediment particles. Since the flow near a spur-dike is very complicated, the 3D modelling has been applied $[9,8]$. However, it does not seem that 3D modelling is quite useful in engineering practices because of choice of turbulence closure, treatment of changing geometry due to erosion and sedimentation and computational expenses. Thus, the 2D approach can be a good alternative in modelling flow near the spur dike.

Previous 2D modellings of flow near the spur dike without sediment transport include [6] and [4]. Tingsanchali and Maheswaran (1990) simulated the flow near a spur dike by using TEACH code, which is based on the depth averaged $k-\epsilon$ turbulence model. Later, [4] solved the same problem with the finite difference model. For the turbulent dissipation terms, the constant eddy viscosity model was employed.

The main objectives of this study are (1) present a numerical model to simulate twodimensional flow near a spur-dike in fixed flat bed. (2) Test the capability of the Computational 
Fluid Dynamics (CFD) program Nays 2D to simulate the flow field. (3) Compare several turbulence models k- $\varepsilon$ model, zero equation model and constant eddy viscosity and compare with respect to the best results.

\section{Model}

The CFD model selected for this study is the publically available software NAYS 2D (iRIC 2.0), which is an analytical solver for calculation of unsteady two-dimensional plane flow and riverbed deformation using boundary-fitted coordinates within general curvilinear coordinates. For the finite-difference method, the CIP method is applied to the advection terms in equations of motion. For the turbulent field calculation, Constant eddy viscosity, Zero-equation model and $\mathrm{K}-\varepsilon$ models are applied and compared.

The basic equations in an orthogonal coordinate system (x, y) before transformation (mapping) into a general curvilinear coordinate system were as follows:

Equations of continuity

$$
\frac{\partial \mathrm{h}}{\partial \mathrm{t}}+\frac{\partial(\mathrm{hu})}{\partial \mathrm{x}}+\frac{\partial(\mathrm{hv})}{\partial \mathrm{y}}=0
$$

Equations of motion

$$
\begin{aligned}
& \frac{\partial(\mathrm{uh})}{\partial \mathrm{t}}+\frac{\partial\left(\mathrm{hu}^{2}\right)}{\partial \mathrm{x}}+\frac{\partial(\mathrm{huv})}{\partial \mathrm{y}}=-\mathrm{hg} \frac{\partial \mathrm{H}}{\partial \mathrm{x}}-\frac{\tau_{\mathrm{x}}}{\rho}+\mathrm{D}^{\mathrm{x}}+\frac{\mathrm{F}_{\mathrm{X}}}{\rho} \\
& \frac{\partial(\mathrm{vh})}{\partial \mathrm{t}}+\frac{\partial(\mathrm{huv})}{\partial \mathrm{x}}+\frac{\partial\left(\mathrm{hv}^{2}\right)}{\partial \mathrm{y}}=-\mathrm{hg} \frac{\partial \mathrm{H}}{\partial \mathrm{y}}-\frac{\tau_{\mathrm{x}}}{\rho}+\mathrm{D}^{\mathrm{y}}+\frac{\mathrm{F}_{\mathrm{y}}}{\rho}
\end{aligned}
$$

in which

$$
\begin{aligned}
& \frac{\tau_{\mathrm{x}}}{\rho}=\mathrm{C}_{\mathrm{f}} \mathrm{u} \sqrt{\mathrm{u}^{2}+\mathrm{v}^{2}}, \frac{\tau_{\mathrm{y}}}{\rho}=\mathrm{C}_{\mathrm{f}} \mathrm{V} \sqrt{\mathrm{u}^{2}+\mathrm{v}^{2}} \\
& \mathrm{D}^{\mathrm{x}}=\frac{\partial}{\partial \mathrm{x}}\left[\mathrm{V}_{\mathrm{t}} \frac{\partial(\mathrm{uh})}{\partial \mathrm{x}}\right]+\frac{\partial}{\partial \mathrm{y}}\left[\mathrm{V}_{\mathrm{t}} \frac{\partial(\mathrm{uh})}{\partial \mathrm{y}}\right] \\
& \mathrm{D}^{\mathrm{y}}=\frac{\partial}{\partial \mathrm{x}}\left[\mathrm{V}_{\mathrm{t}} \frac{\partial(\mathrm{vh})}{\partial \mathrm{x}}\right]+\frac{\partial}{\partial \mathrm{y}}\left[\mathrm{V}_{\mathrm{t}} \frac{\partial(\mathrm{vh})}{\partial \mathrm{y}}\right] \\
& \frac{F_{x}}{\rho}=\frac{1}{2} C_{D} \alpha_{S} h u \sqrt{u^{2}+v^{2}}, \frac{F_{y}}{\rho}=\frac{1}{2} C_{D} \alpha_{s} h v \sqrt{u^{2}+v^{2}}
\end{aligned}
$$

where $\mathrm{h}$ is water depth, $\mathrm{t}$ is time, $\mathrm{u}$ is velocity in the $\mathrm{x}$ direction, $\mathrm{v}$ is velocity in the $\mathrm{y}$ direction, $\mathrm{g}$ is gravitational acceleration, $\mathrm{H}$ is water depth, $\tau_{\mathrm{x}}$ is riverbed shearing force in the $\mathrm{x}$ direction, $\tau_{\mathrm{y}}$ is riverbed shearing force in the $\mathrm{y}$ direction, $\mathrm{F}_{\mathrm{x}}$ is resistance by vegetation in the $\mathrm{x}$ direction, $\mathrm{F}_{\mathrm{y}}$ is resistance by vegetation in the $y$ direction, $\mathrm{C}_{\mathrm{f}}$ is riverbed shear coefficient, $v_{\mathrm{t}}$ is eddy viscosity coefficient, $C_{D}$ is drag coefficient of vegetation, and $a_{s}$ is area of interception by vegetation per unit volume.

Next, basic equations of two-dimensional plane flow at orthogonal coordinates are transformed into general coordinates $(\xi, \eta)$. By transforming the equations into general coordinates, it becomes possible to set a calculation mesh of any shape (in keeping with the boundary conditions). The following describes how the equations can be transformed from orthogonal coordinates into general curvilinear coordinates 


$$
\begin{aligned}
& \frac{\partial}{\partial x}=\frac{\partial \xi}{\partial x} \frac{\partial}{\partial \xi}+\frac{\partial \eta}{\partial x} \frac{\partial}{\partial \eta} \\
& \frac{\partial}{\partial y}=\frac{\partial \xi}{\partial y} \frac{\partial}{\partial y}+\frac{\partial \eta}{\partial y} \frac{\partial}{\partial \eta}
\end{aligned}
$$

Or,

$$
\left[\begin{array}{c}
\frac{\partial}{\partial x} \\
\frac{\partial}{\partial y}
\end{array}\right]\left[\begin{array}{cc}
\xi_{x} & \eta_{x} \\
\xi_{y} & \xi_{y}
\end{array}\right]=\left[\begin{array}{c}
\frac{\partial}{\partial \xi} \\
\frac{\partial}{\partial x}
\end{array}\right]
$$

Where,

$$
\begin{aligned}
& \xi_{\mathrm{x}}=\frac{\partial \xi}{\partial \mathrm{x}}, \xi_{\mathrm{y}}=\frac{\partial \xi}{\partial \mathrm{y}}, \eta_{\mathrm{x}}=\frac{\partial \eta}{\partial \mathrm{x}}, \eta_{\mathrm{y}}=\frac{\partial \eta}{\partial \mathrm{y}} \\
& \frac{\partial}{\partial \xi}=\frac{\partial x}{\partial \xi} \frac{\partial}{\partial x}+\frac{\partial y}{\partial \xi} \frac{\partial}{\partial y} \\
& \frac{\partial}{\partial x}=\frac{\partial x}{\partial \eta} \frac{\partial}{\partial x}+\frac{\partial y}{\partial \eta} \frac{\partial}{\partial y}
\end{aligned}
$$

Or,

$$
\left[\begin{array}{c}
\frac{\partial}{\partial \xi} \\
\frac{\partial}{\partial x}
\end{array}\right]=\left[\begin{array}{ll}
x_{\xi} & y_{\xi} \\
x_{\eta} & y_{\eta}
\end{array}\right]\left[\begin{array}{c}
\frac{\partial}{\partial x} \\
\frac{\partial}{\partial y}
\end{array}\right]
$$

Where,

$$
x_{\xi}=\frac{\partial}{\partial \xi}, x_{\eta}=\frac{\partial x}{\partial \eta}, y_{\xi}=\frac{\partial y}{\partial \xi}, y_{\eta}=\frac{\partial y}{\partial \eta}
$$

\section{Application}

For validation, the model is applied to the flow near a spur dike in a fixed bed (Fig 2). The computational conditions used herein are the same as the ones in case A1 in experiment [5]. The channel is $5 \mathrm{~m}$ long and $0.9 \mathrm{~m}$ wide. The spur-dike having length $0.15 \mathrm{~m}$ and thickness $0.01 \mathrm{~m}$ is located vertically $2 \mathrm{~m}$ downstream from the upstream end. The discharge is $0.0175 \mathrm{~m}^{3} / \mathrm{s}$. For boundary conditions, water surface at downstream and velocity at upstream are considered uniform flow. Slope for uniform flow is calculated from geographical data.

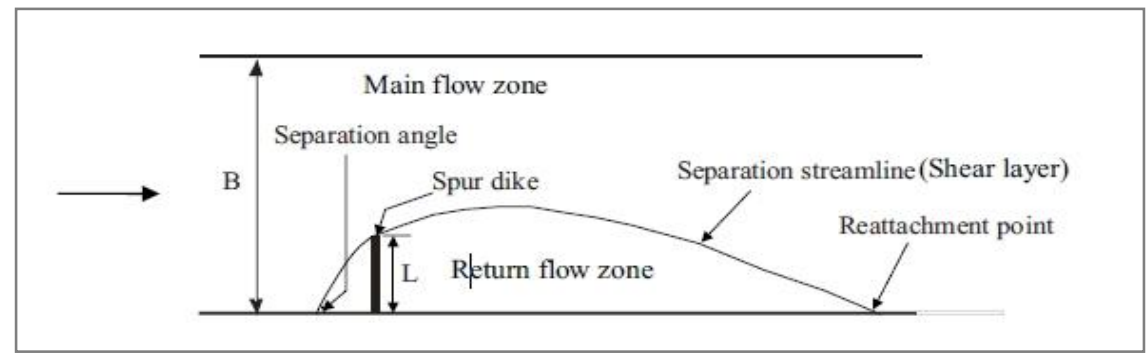

Figure 1: Schematic sketch of 2D flow near a spur dike 


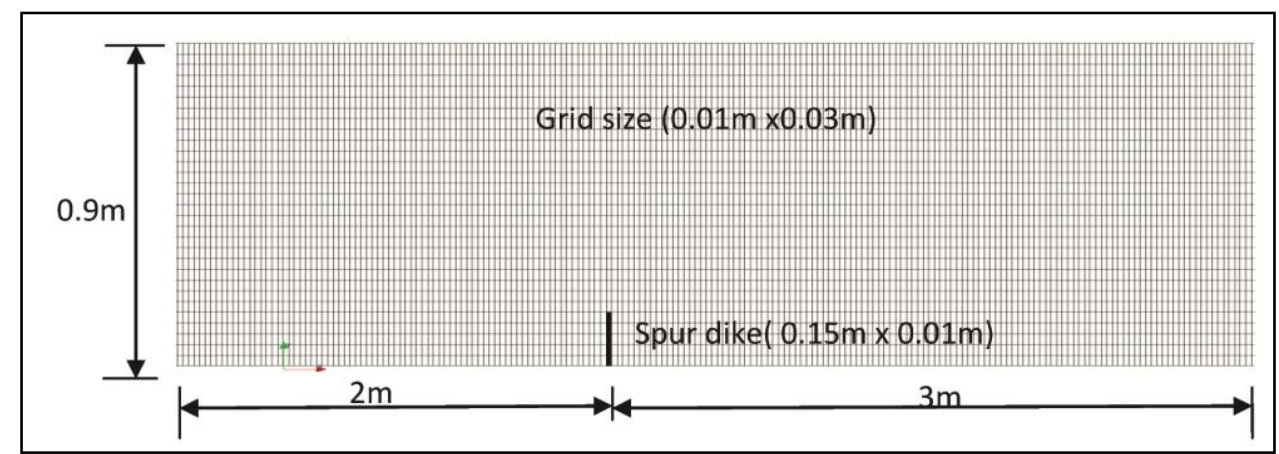

Figure 2: Computational grid

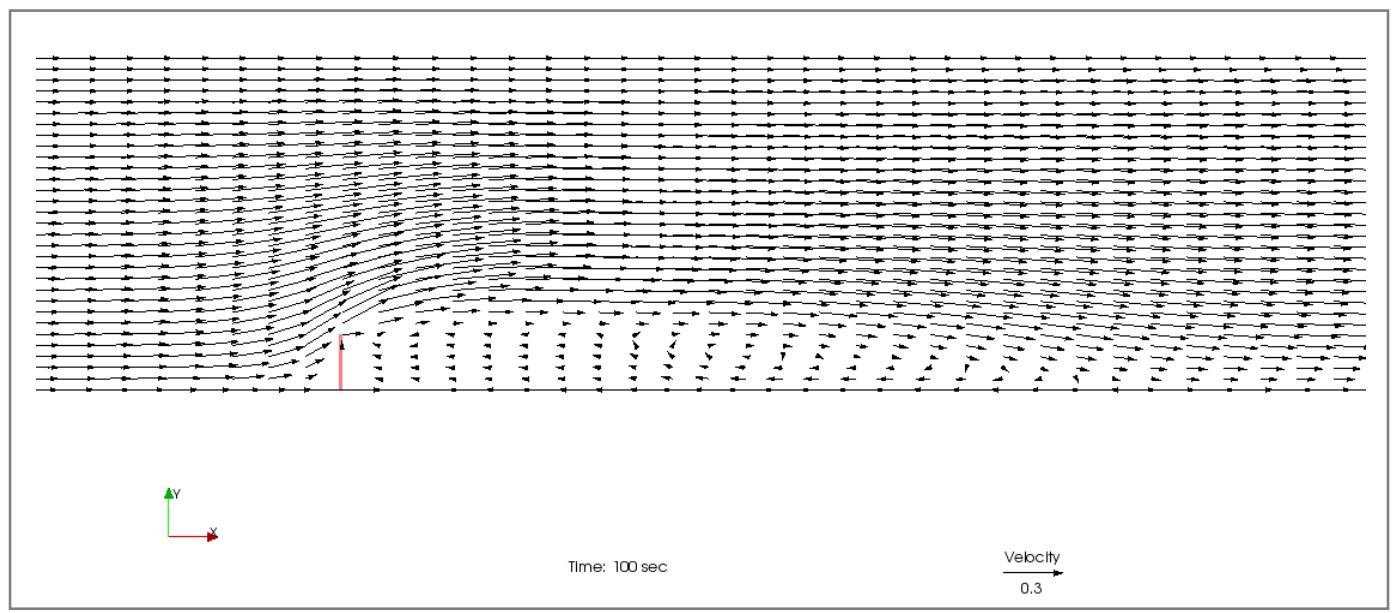

Figure 3: Computed velocity vector field

For numerical simulation, the computational grids are generated as shown in Fig 2. 501 grids having size of each grid $0.01 \mathrm{~m}$ along the stream-wise direction (x-axis) and 31 grids having the size $0.03 \mathrm{~m}$ along the cross stream direction (y-axis) are constructed to minimize the effect of numerical dissipation. To ensure that the results are independent of grid size distribution, a few computational trials are carried out with different number of grids in $\mathrm{x}$ - and $\mathrm{y}$ - directions.

Fig 3 shows the computed vector field of established flow near the spur dike. It is seen in the figure that flow accelerates by the reduction of cross section due to the spur dike. Also it is observed that separation starts at the tip of spur dike and reattachment occurs at a downstream point. In between, recirculation zone is formed. From the figure, the reattachment length and the maximum width of the recirculation zone are estimated to be 12 times and 2 times the length of spur dike respectively. Table 1 lists various values of reattachment length and maximum width of the recirculation zone available in the previous studies which compare favorably to the length and maximum width from present model. 
Table 1: Length and width of the recirculation zone

\begin{tabular}{|l|c|c|c|}
\hline \multicolumn{1}{|c|}{ Researcher } & $\mathbf{L}_{\mathbf{1}}{ }^{*}$ & $\mathbf{W}^{*}{ }_{\text {max }}$ & Computational Method \\
\hline Francis et al. & 12.5 & N/A & Experiment \\
\hline Rajaratnam \& Nwachukwu (1983) & 12 & 2 & Experiment \\
\hline Holtz (1991) & 11.5 & N/A & Experiment/ Numerical Simulation \\
\hline Tingsanchali \& Maheswaran (1990) & $10.0-12.0$ & 2 & Numerical Simulation 2D \\
\hline Ouillon \& Dartus (1997) & 10.7 & 1.9 & Numerical Simulation 2D \\
\hline Mayerle et al. (1995) & $8.4-15.2$ & N/A & Numerical Simulation 3D \\
\hline Molls et al. (1995) & 12 & 1.85 & Numerical Simulation 2D \\
\hline Ettema \& Muste (2004) & $13.0-14.0$ & N/A & Experiment \\
\hline Sung Choi et al. (2004) & 12.5 & 2 & Numerical Simulation 2D \\
\hline Present Study & 12 & 2 & Numerical Simulation 2D \\
\hline \multicolumn{2}{|c|}{$\mathrm{L}_{1}{ }^{*}=$ Non-dimensional recirculation length (x/b) } \\
$\mathrm{W}^{*}{ }_{\text {max }}=$ Non-dimenstional recirculation width (y/b)
\end{tabular}

\section{Comparison between computed results and experimental data}

The computed depth averaged U-velocity profiles are compared with the data of experiment A1 conducted by [5] and also compared with computed values for the same by [6]. It is shown that in the region of main flow where the maximum velocity occurs, i. e $1 \leq y / b \leq 6$ and $-6 \leq x / b \leq 8$, the computed resultant velocity distribution profiles agree reasonably well with experimental data.

Sensitivity analysis and model calibration are carried out with different parameters- Manning's roughness coefficient, relaxation coefficient, finite differential method for advection terms and turbulence closure models. The model is run for different relaxation coefficients $0.2,0.4,0.6$ and 0.8 for water surface calculations. Different values of this parameter did not change the output results. The model is very sensitive with values of Manning's roughness coefficient (n). Resultant velocity is inversely proportional to the value of roughness coefficient. Higher the values of roughness results the lower value of resultant velocity and vice-versa. The model is also run for both finite differential methods for advection terms i. e upwind scheme and CIP method. The output results are same for both schemes. So, in this study CIP method is adopted.

To compare the simulated results from NAYS 2D using different turbulence closure models, statistical parameters are calculated for the errors between the simulated and experimental data in Table 2. Four statistical measures of model predictions are adapted in this study. The Rsquared correlation that measures the model's accuracy in predicting velocities in two dimensions. The model's accuracy in predicting the velocity magnitudes is evaluated using mean absolute error (MAE), mean square error (MSE), and root mean square error (RMSE). The comparison of results shows the importance of selecting an appropriate turbulence model in simulating flow field around a spur dike. From the comparison, $\mathrm{k}-\epsilon$ model is found superior over zero energy model and eddy viscosity model. So, $\mathrm{k}-\epsilon$ model is chosen as appropriate turbulence closure model. 
Table 2: Statistical comparison of the experimental and modeled results for the fixed bed

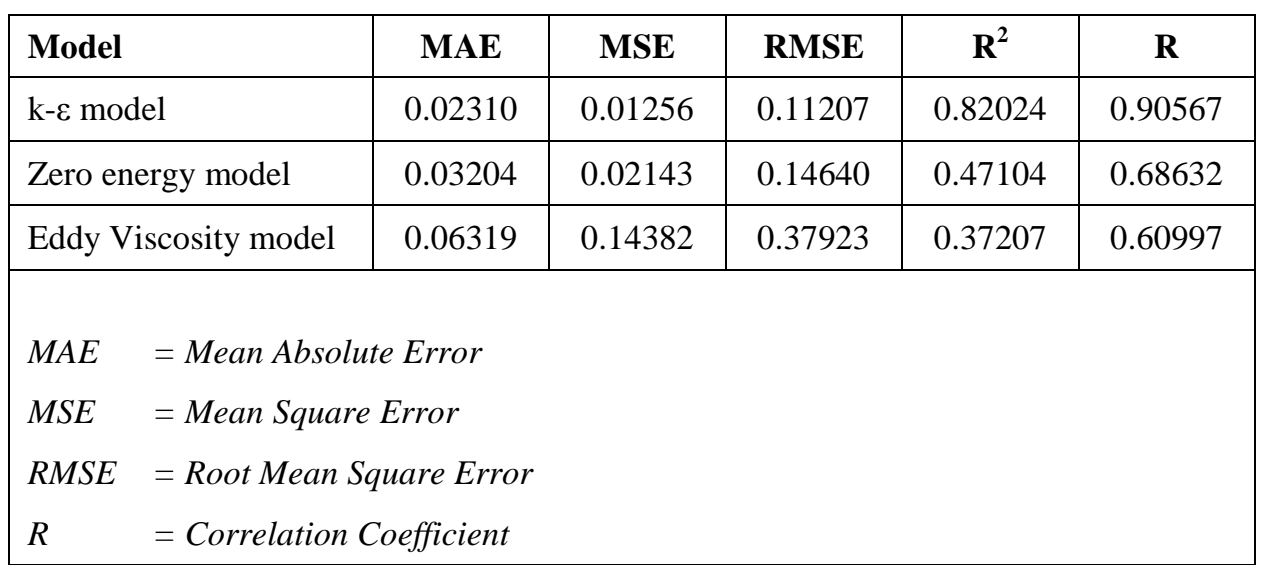

\section{Conclusions}

This study employed a numerical model NAYS 2D for simulation of flow near a spur dike in fixed flat bed. Cubic-interpolated pseudo-particle (CIP) method was used as a finite differential method for advection terms. For turbulence closure, k-€ model, zero equation model and eddy viscosity models were used and compared with statistical parameters. From the comparison, k- $\epsilon$ model was found superior over rest of two models. The model was applied to a case in [5] A1 experiment. The computed vector field showed flow acceleration by the spur dike properly. In the recirculation zone behind the spur-dike, reattachment length and the maximum width appear to 12 and 2 times the length of spur-dike, which confirms well to previous results in literatures. The computed resultant velocity profiles were compared with the experimental data of [5] and computed results by [6] which agreed satisfactorily. Achieved results can prove that flow structure simulation around a spur dike could be done by Nays 2D numerical modelling very well.

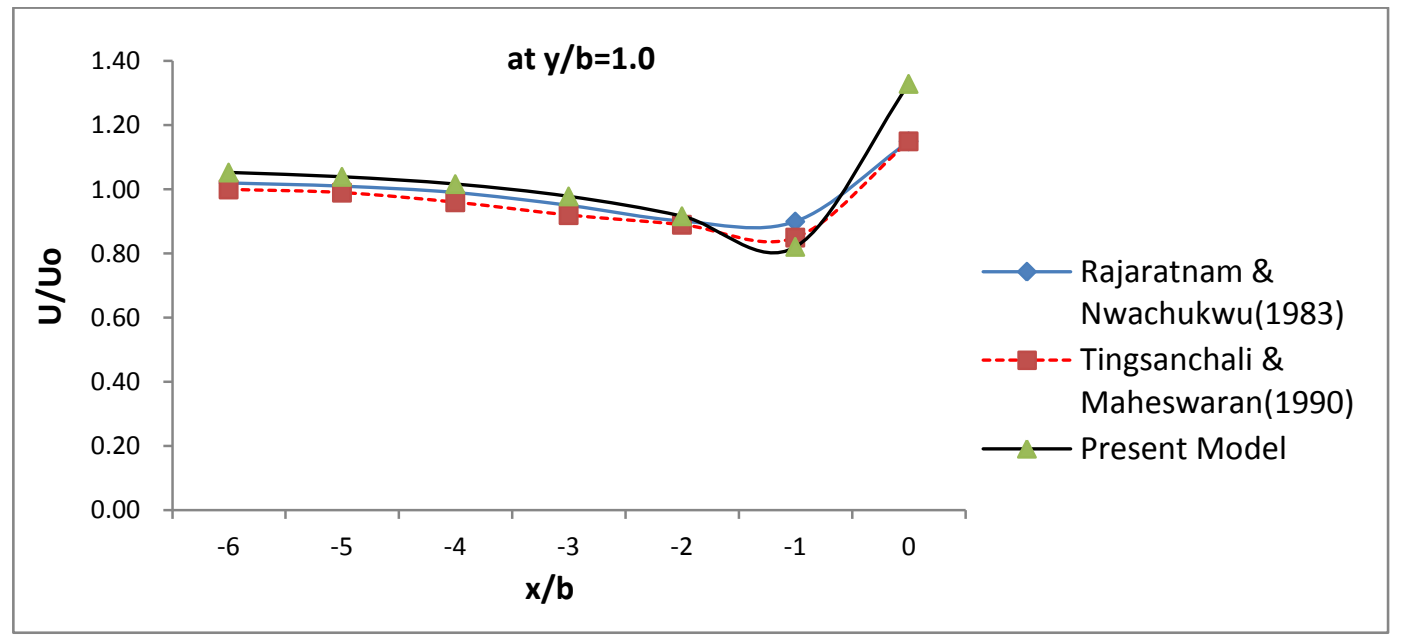

(a) 


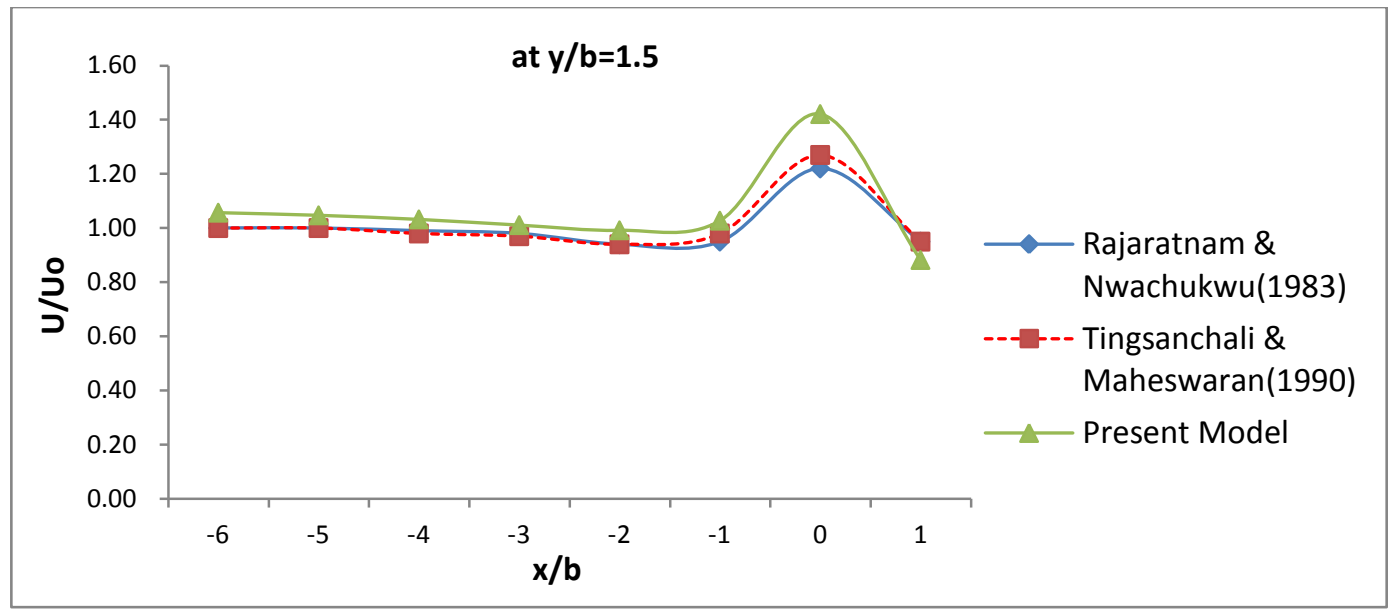

(b)

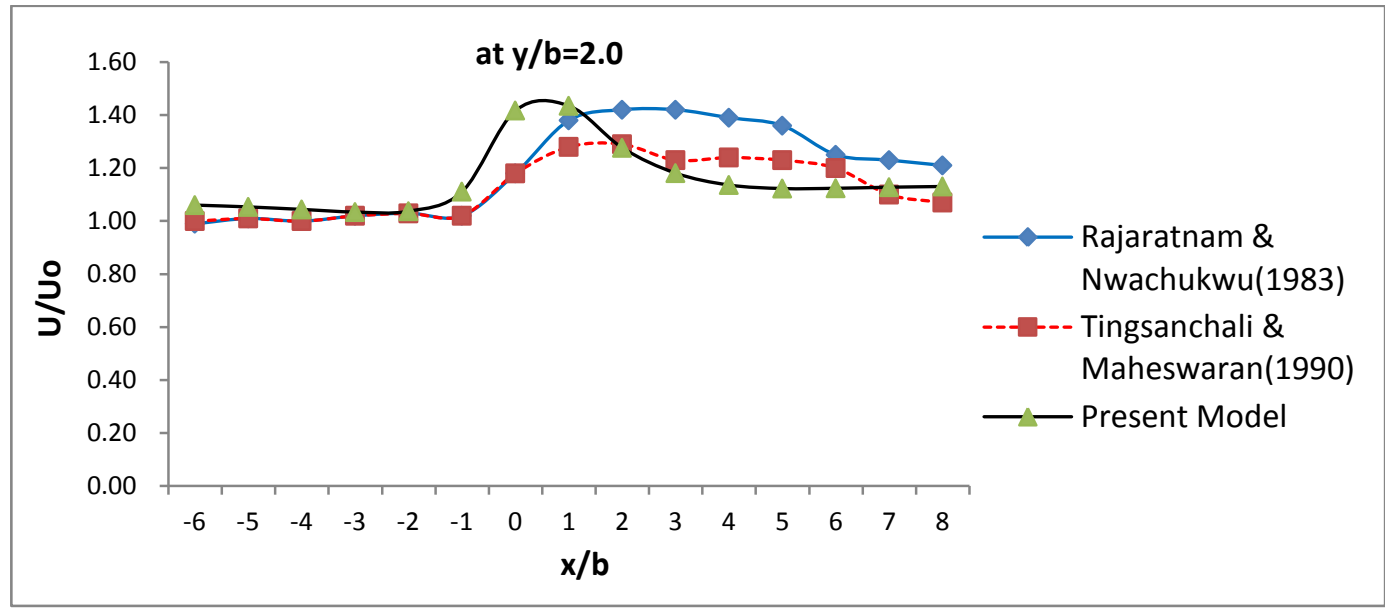

(c)

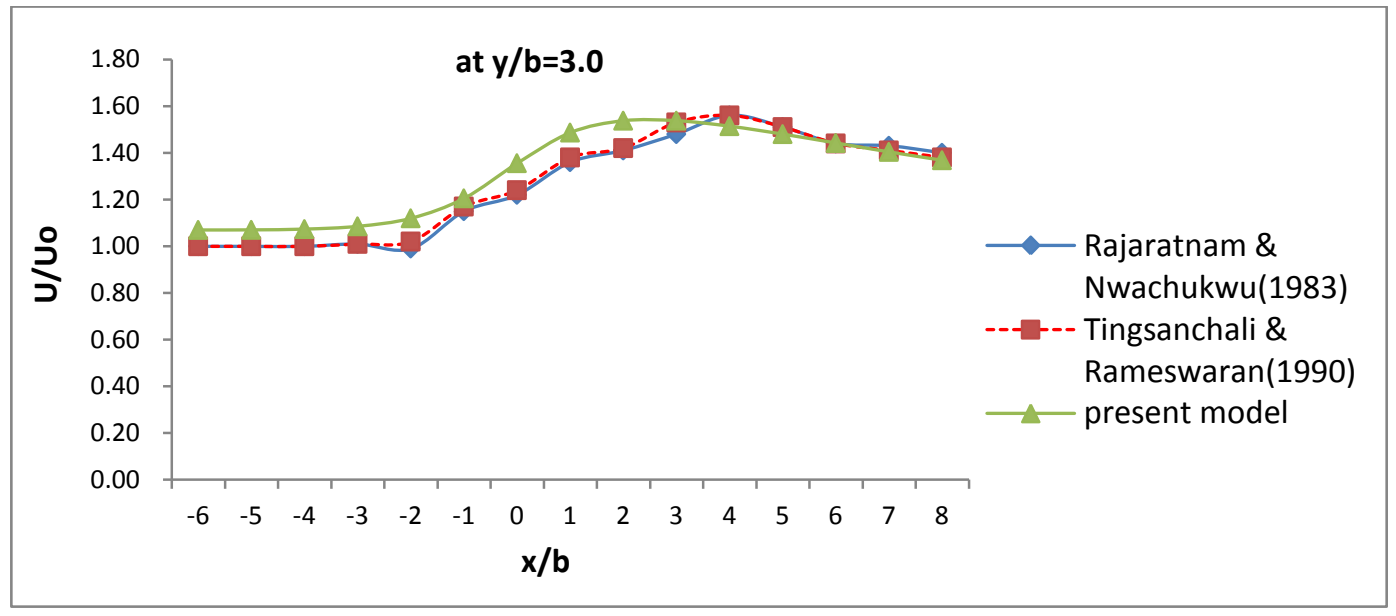

(d) 


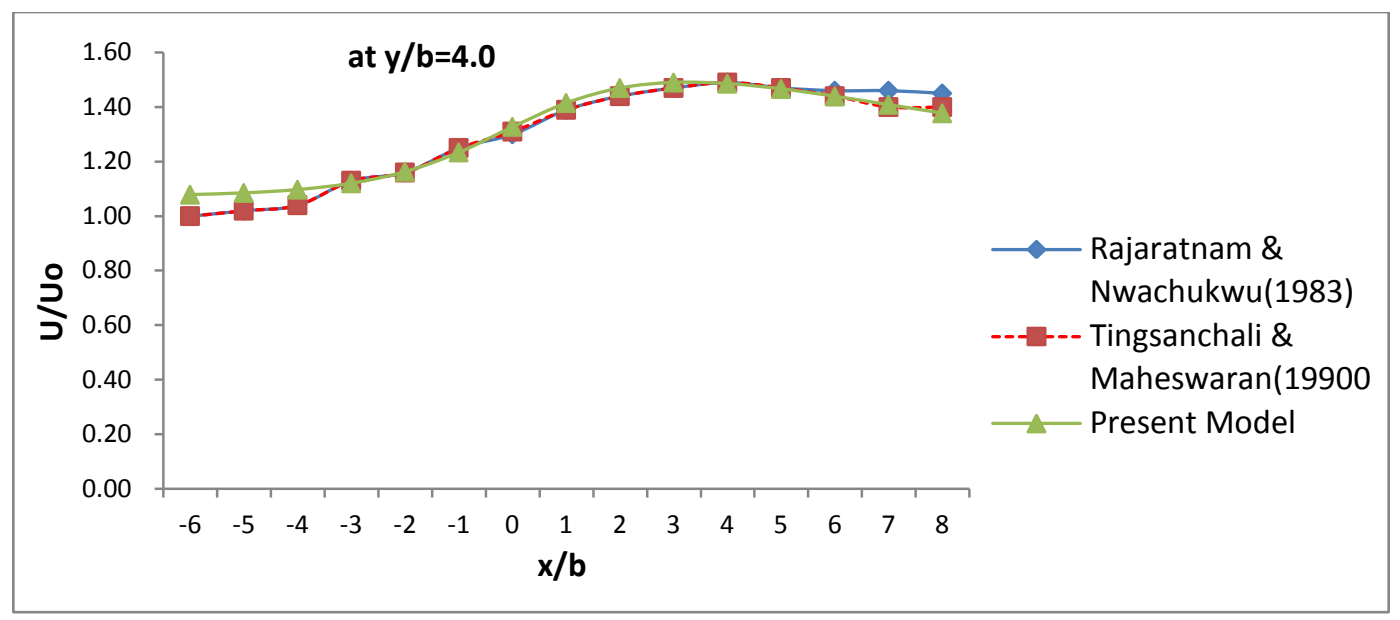

(e)

Figure 4: Computed velocity magnitude profiles

\section{References}

[1] Shimizu, Y, and Nelson, J. (2012). Introduction of Nays solver in iRIC, www.i-ric.org.

[2] Choi, S., Dongwon, O. (2004). Finite element modeling of shallow water equations for numerical simulation of flows near spur-dike, Advances in Hydro-Science and Engineering, Volume VI, 1-9.

[3] Holtz, K. P. (1991). Numerical simulation of recirculating flow at groynes, Computer Methods in Water Resources, 2(2), 463-477.

[4] Molls, T, Chaudhary, M. H, Khan, K. W. (1995). Numerical simulation of two -dimensional flow near a spur-dike, Advances in Water Resources, 18(4), 227-236.

[5] Rajaratnam, M. N, Nwachukwu, B. A. (1983). Flow near groin-like structure, Journal of Hydraulic Engineering, ASCE,109(3), 463-480.

[6] Tingsanchali, T, Maheswaran, S. (1990). 2-D depth-average flow computation near groyne, Journal of Hydraulic Engineering, ASCE, 116(1), 71-86.

[7] Shields, F. D., Knight, S. S, Cooper, C. M. (2000). Warm water stream bank protection and fish habitat: a comparative study, Environmental Management, 26(3), 317-328.

[8] Ouillon, S, Dartus, D. (1997). Three-dimensional computation of flow around groyne, Journal of Hydraulic Engineering, ASCE, 123(11), 962-970.

[9] Mayerle, R, Toro, F. M, Wang, S. S. Y. (1995). Verification of a three-dimensional numerical model simulation of the flow in the vicinity of spur dikes, Journal of Hydraulic Research, IAHR, 33(2), 243-256.

[10] Acharya, A., Duan, J. G. (2011). Three dimensional simulation of flow around series of spur dikes, Journal of Hydraulic Engineering, ASCE. 